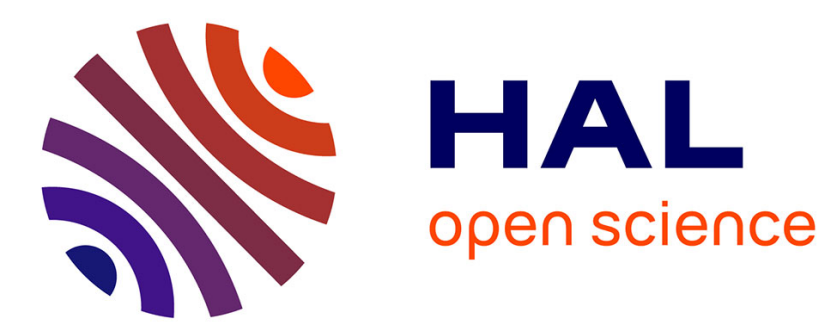

\title{
Contributions of oxygen vacancies and titanium interstitials to band-gap states of reduced titania
}

Jingfeng Li, Rémi Lazzari, Stéphane Chenot, Jacques Jupille

\section{To cite this version:}

Jingfeng Li, Rémi Lazzari, Stéphane Chenot, Jacques Jupille. Contributions of oxygen vacancies and titanium interstitials to band-gap states of reduced titania. Physical Review B: Condensed Matter and Materials Physics (1998-2015), 2018, 97 (4), pp.041403. 10.1103/PhysRevB.97.041403 . hal01700847

\section{HAL Id: hal-01700847 \\ https://hal.sorbonne-universite.fr/hal-01700847}

Submitted on 5 Feb 2018

HAL is a multi-disciplinary open access archive for the deposit and dissemination of scientific research documents, whether they are published or not. The documents may come from teaching and research institutions in France or abroad, or from public or private research centers.
L'archive ouverte pluridisciplinaire HAL, est destinée au dépôt et à la diffusion de documents scientifiques de niveau recherche, publiés ou non, émanant des établissements d'enseignement et de recherche français ou étrangers, des laboratoires publics ou privés. 


\title{
Contributions of oxygen vacancies and titanium interstitials to the band gap states of reduced titania
}

\author{
Jingfeng Li, ${ }^{*}$ Rémi Lazzari, ${ }^{\dagger}$ Stéphane Chenot, ${ }^{\ddagger}$ and Jacques Jupille ${ }^{\S}$ \\ CNRS, Sorbonne Universités, UPMC Univ Paris 06, UMR 7588, \\ Institut des NanoSciences de Paris, 75005 Paris, France
}

(Dated: December 22, 2017)

\begin{abstract}
The spectroscopic fingerprints of the point defects of titanium dioxide remain highly controversial. Seemingly indisputable experiments lead to conflicting conclusions in which oxygen vacancies and titanium interstitials are alternately referred to as the primary origin of the Ti $3 \mathrm{~d}$ band gap states. We report on experiments performed by electron energy loss spectroscopy whose key is the direct annealing of only the very surface of rutile $\mathrm{TiO}_{2}(110)$ crystals and the simultaneous measurement of its temperature via the Bose-Einstein loss/gain ratio. By surface preparations involving reactions with oxygen and water vapor, in particular under electron irradiation, vacancies- and interstitialsrelated band gap states are singled out. Off-specular measurements reveal that both types of defects contribute to a unique charge distribution that peaks in subsurface layers with a common dispersive behavior.
\end{abstract}

Already used in self-cleaning coatings and dyesensitized solar cells, titanium dioxide $\mathrm{TiO}_{2}$ offers promising solutions to water/air purification and water splitting ${ }^{42,43}$. Its rich physics and chemistry is mostly tied to the reduced $\mathrm{TiO}_{2-x}$ form in which dominant points defects, bridging oxygen vacancies $\left(\mathrm{O}_{b}\right.$-vac $)$ and titanium interstitials $\left(\mathrm{Ti}_{\text {int }}\right)$ widely explored on rutile $(110)^{43-47}$ (Fig. 1), play a pivotal role. At the origin of the n-type electron conductivity, excess electrons generated by defects populate Ti $3 \mathrm{~d}$ related band gap states (BGS). They have long been associated to $\mathrm{O}_{b}$-vac (herein labelled V-BGS) because $\mathrm{O}_{2}$ dissociation both eliminates $\mathrm{O}_{b}$-vac and heals them by a charge transfer toward $\mathrm{O}_{b}$ and $\mathrm{O}$ adatoms $\left(\mathrm{O}_{a d}\right)$ adsorbed on fivecoordinated $\mathrm{Ti}_{5 c}{ }^{48}$. The model became hotly debated when vacancy-free $\mathrm{TiO}_{2}(110)$ obtained by reacting off $\mathrm{H}$ from hydroxylated $\mathrm{TiO}_{2-x}$ was shown to retain most BGS that were consequently related to $\mathrm{Ti}_{\text {int }}$ (I-BGS $)^{45}$. Their healing by $\mathrm{O}_{2}$ was explained by a charge donation from $\mathrm{Ti}_{\text {int }}$ that promotes a non-vacancy-related $\mathrm{O}_{2}$ dissociation $^{45}$. Consistently, the $\mathrm{TiO}_{x}$ islands formed upon annealing O-covered rutile ${ }^{45,49-53}$ were attributed to reaction of $\mathrm{O}_{a d}$ with $\mathrm{Ti}_{\text {int }}$ which, like the reoxidation of $\mathrm{TiO}_{2-x}{ }^{54}$, relies on the diffusion of $\mathrm{Ti}_{\text {int }}$ in rutile above $400 \mathrm{~K}$. Finally, extra $\mathrm{O}_{a d}$ atoms (relative to dissociation on $\mathrm{O}_{b}$-vac) obtained by reacting $\mathrm{O}_{2}$ with $\mathrm{TiO}_{2-x}$, were associated to charge transfer from $\mathrm{Ti}_{\text {int }}{ }^{45,55}$. Additional supports to the $\mathrm{O}$-vacancy model ${ }^{48}$ feeded the controversy. The oxidative chemistry of $\mathrm{TiO}_{2-x}$ was suggested to be controlled by donor species $\left(\mathrm{O}_{b}\right.$-vac and $\left.\mathrm{OH}\right)$ rather than $\operatorname{Ti}_{\text {int }}{ }^{56}$ and, based on a relationship of proportionality between $\mathrm{O}_{b}$-vac counting by microscopy and photoemission signal, BGS appeared to mostly stem from $\mathrm{O}_{b}-\mathrm{vac}^{57}$.

The crux of the debate is that the signatures of V-BGS and I-BGS look identical. The case is tackled herein by the rarely used high-resolution electron-energy loss spectroscopy (HREELS). The key experiment to single out BGS contributions is the quick annealing (up to $1000 \mathrm{~K}$ within a few seconds) of the surface only via a

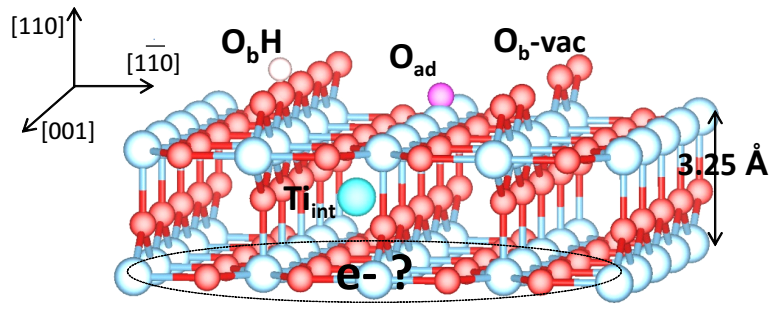

FIG. 1. Ball model of defective $\mathrm{TiO}_{2}(110)$ (Ti, O, H, Ti $\mathrm{Tin}_{\text {int }}$, $\mathrm{O}_{a d}$ are blue, red, white, cyan and pink spheres, respectively); bridging oxygen rows involve $\mathrm{O}_{b}$-vac and $\mathrm{O}_{b} \mathrm{H} ; \mathrm{O}_{a d}$ lie on $\mathrm{Ti}_{5 c}$; $\mathrm{Ti}_{\text {int }}$ occupy octahedral sites ${ }^{58}$; the localisation of excess electrons (question mark) associated to defects is under debate.

hot filament facing the crystal within the spectrometer, while probing $\mathrm{T}$ (temperature) via the Bose-Einstein statistics (Fig. S1 in Supplemental Material ${ }^{59}$ ) of the loss/gain phonon ratio. -Annealed samples are labelled $\mathrm{SA}-\mathrm{T}-\mathrm{TiO}_{2}$ hereafter. Controversial or unexplained data involving annealing treatments, electron bombardment and exposures to $\mathrm{O}_{2}$ and $\mathrm{H}_{2} \mathrm{O}$, have been revisited to feature I-BGS and V-BGS. Finally, BGS in-depth profiles $^{60-64}$ were probed by off-specular EELS.

$\mathrm{TiO}_{2}(110)$ single crystals were mounted in an ultrahigh vacuum (UHV) set-up ${ }^{65}$ equipped with an EELS spectrometer (Sect. S1 in Supplemental Material ${ }^{59}$ ). Sputering and annealing $\mathrm{TiO}_{2}(110)$ resulted in reduced dark blue color samples $\mathrm{R}-\mathrm{TiO}_{2}$ of which surfaces could be reoxidized $\left(\mathrm{O}-\mathrm{TiO}_{2}\right)$ by 30 mins annealing $(1100 \mathrm{~K})^{50}$ and cooling in $\mathrm{O}_{2}\left(5 \times 10^{-6} \mathrm{mbar}\right)$ at a rate of $\sim 30 \mathrm{~K} \cdot \mathrm{min}^{-1}$ (Sect. S1 in Supplemental Material ${ }^{59}$ ). EEL spectra were collected between $100 \mathrm{~K}$ and $300 \mathrm{~K}$. Unless stated, they were recorded in specular geometry (incident angle $\Theta_{I}=60^{\circ}$, incident plane along [11̄0] direction) at an energy of $E_{I}=38 \mathrm{eV}$. Typical EELS spectra (Fig. S3 in Supplemental Material ${ }^{59}$ ) show 
broad BGS features at $\sim 0.8 \mathrm{eV}$ before the onset of band-to-band excitations at $3.2 \mathrm{eV}$. Bulk sensitivity at phonon energies provides a reliable intensity normalization (Sect. S3 in Supplemental Material ${ }^{59}$ ). Exposures are expressed in Langmuir $\left(1 \mathrm{~L}=1.33 \times 10^{-6}\right.$ mbar. $\left.\mathrm{s}^{-1}\right)$. EELS spectra recorded on $\mathrm{R}-\mathrm{TiO}_{2}$ at $100 \mathrm{~K}$ (Fig. S3a in Supplemental Material ${ }^{59}$ ) and $300 \mathrm{~K}$ (Fig. S3b in Supplemental Material ${ }^{59}$ ) under $\mathrm{O}_{2}$ show progressive BGS healing, although kinetics are different. Fast and slow decrease in BGS intensity that are observed at 100 $\mathrm{K}$ and $300 \mathrm{~K}$, respectively, rely on mechanisms that are under debate ${ }^{51,54,66}$. Importantly, the similarity of the final BGS intensities (Fig. S3a-inset in Supplemental Material $^{59}$ ) indicates two equivalent healing processes.

The preparation of $\mathrm{SA}-\mathrm{TiO}_{2}$ surfaces is central in pinpointing categories of point defects. An indisputable proof of the existence of I-BGS is provided by the defect peak growing on $\mathrm{SA}-420 \mathrm{~K}-\mathrm{TiO}_{2}$ (Fig. 2a). The formation of $\mathrm{O}_{b}$-vac at $420 \mathrm{~K}$ being excluded, this peak is assigned to I-BGS formed via an outward $\mathrm{Ti}_{\text {int }}$ diffusion ${ }^{45,67-69}$ as supported by the square root of time dependence of the BGS intensity (Fig. 2a-inset).

In contrast to the slow kinetics of BGS formation on SA-420K-TiO 2 (Fig. 2a), $\mathrm{SA}_{-}-\mathrm{TiO}_{2}$ surfaces prepared by annealing of $10 \mathrm{~s}$ above $800 \mathrm{~K}$ (Fig. 2b) show strong BGS whose intensity rises with $\mathrm{T}$. Indeed, $\mathrm{O}_{b}$-vac are expected to form ${ }^{44}$, but it is unclear whether defect states are I-BGS or V-BGS. More is learned on I-BGS by preparing $\mathrm{SA}_{-} \mathrm{TiO}_{2}$ at increasing temperature followed by $20 \mathrm{~L}$ of $\mathrm{O}_{2}$ at $300 \mathrm{~K}$ (Fig. 2c, steps 1 to 4; inset: BGS intensities). Firstly, healing I-BGS from SA-420K- $\mathrm{TiO}_{2}$ by $\mathrm{O}_{2}$ (step 1) validates the non-vacancy-related $\mathrm{O}_{2}$ dissociation associated to charge transfer from $\mathrm{Ti}_{\text {int }}{ }^{45,55}$. Then, increasing BGS are observed on SA-970K- $\mathrm{TiO}_{2}$ and $\mathrm{SA}-1140 \mathrm{~K}-\mathrm{TiO}_{2}$ although, surprisingly, the residual BGS observed after $\mathrm{O}_{2}$ exposure continuously decreases through steps $1,2,4$ (Fig. 2c). Extra-healing of $\mathrm{O}_{b}$-vac is excluded since there is no reason why reacting $\mathrm{O}_{b}$-vac with $20 \mathrm{~L}$ of $\mathrm{O}_{2}$ should leave fewer $\mathrm{O}_{b}$-vac sites intact while their initial concentration is higher. Therefore, Fig. 2c shows that the commonly observed residual BGS (Fig. S4 in Supplemental Material ${ }^{59}$ and Refs. ${ }^{45,57,66}$ ) mostly involve I-BGS. Annealing O-covered surfaces at increasing temperature triggers outward $\mathrm{Ti}_{\text {int }}$ diffusion $^{51,70}$ from increasingly deeper layers. Assuming that $\mathrm{Ti}_{\text {int }}$ segregate on step $2\left(\mathrm{SA}-970 \mathrm{~K}-\mathrm{TiO}_{2}\right)$ over deeper layers than that reached by $\mathrm{SA}-420 \mathrm{~K}-\mathrm{TiO}_{2}$ (step 3) explains the marginal BGS change on step 3, in apparent contrast with step 1 . The depletion in subsurface $\mathrm{Ti}_{\text {int }}$ which progressively extends inward (step 1 to 4 , Fig. 2c) suggests that annealing/oxidation cycles can lead to a BGS-free surface region.

The existence of V-BGS has not been singled out yet. Often accepted $^{57}$, the attribution to V-BGS of $\mathrm{O}_{b}$-vac created by electron stimulated desorption (ESD) via the Knotek-Feibelmann process ${ }^{71,72}$ is nevertheless strongly discussed ${ }^{73,74}$. Electron bombarded surfaces $\left(\mathrm{E}-\mathrm{TiO}_{2}\right)$ were prepared by illuminating $\mathrm{O}-\mathrm{TiO}_{2}$ by a $75 \mathrm{eV}$ electron beam (current density $\left.\sim 1 \mu \mathrm{A} . \mathrm{cm}^{-2}\right)^{71,72}$. Totally healed at $100 \mathrm{~K}$ by only $1 \mathrm{~L} \mathrm{O}_{2}$ (Fig. 3a), the resulting BGS thus stem from very surface defects but, still, there is no indisputable evidence that they are V-BGS. A clue came from the observation that ESD-induced BGS level off at rather low intensity after $5 \mathrm{~min}$, to remain stable for hours (not shown). Comparison with other groups show that rather weak BGS were obtained with electron fluxes of $1.2510^{12} \mathrm{e} . \mathrm{cm}^{-2} . \mathrm{s}^{-175}$ and $6.2510^{12} \mathrm{e} . \mathrm{cm}^{-2} . \mathrm{s}^{-1}$ (this work) while $1.2510^{15} \quad$ e.cm ${ }^{-2} . \mathrm{s}^{-157}$ and $310^{15} \mathrm{e} . \mathrm{cm}^{-2} \cdot \mathrm{s}^{-156}$ led to strong BGS, although fluences were similar $\left(310^{15}\right.$ e.cm ${ }^{-275} ; 210^{15}$ e.cm ${ }^{-2}$ (this work); $6-2510^{15}$ e.cm $^{-257}$ ). Clearly, the electroninduced BGS intensity depends on the flux rather than on the fluence, which suggests a continuous healing of related $\mathrm{O}_{b}$-vac. We may wonder what is the combined effect of residual water and ESD removal of $\mathrm{H}$ adatoms (threshold at 21-22 $\mathrm{eV}^{71,72}$ ). Although reacting $\mathrm{O}_{b}$-vac by $\mathrm{H}_{2} \mathrm{O}$ does not heal $\mathrm{BGS}^{45,76-78}, \mathrm{H}_{2} \mathrm{O}$ under $38 \mathrm{eV}$ electrons does heal BGS of SA-970K-TiO 2 (Fig. 3b). Consistently, $22 \mathrm{eV}$ electrons (threshold for H ESD) have no effect (Fig. 3c). In contrast, I-BGS from $\mathrm{SA}-420 \mathrm{~K}-\mathrm{TiO}_{2}$ are not healed at $38 \mathrm{eV}$ when exposed to $\mathrm{H}_{2} \mathrm{O}$ (Fig. 3d), although, as in Fig. 2d (step 1), they are healed by $\mathrm{O}_{2}$. Beyond the demonstration of the existence of V-BGS and I-BGS, the healing of V-BGS via $\mathrm{H}_{2} \mathrm{O}$ adsorption provides a mean of distinguishing the two states, as in Fig. 3e, where $\mathrm{R}-\mathrm{TiO}_{2}$ is exposed to $\mathrm{H}_{2} \mathrm{O}$, under a $38 \mathrm{eV}$ electron beam (healing V-BGS) and then exposed to $\mathrm{O}_{2}$ (healing I-BGS). Notably, the plateau reached by the intensity of the ESD-induced BGS supports their V-BGS nature because, if I-BGS were created, the inability of $\mathrm{H}_{2} \mathrm{O}$ to heal them would result in a continuous increase in their intensity.

Finally, the concentration profiles of the excess electrons and the dispersion of the associated BGS were explored by off-specular EELS (Fig. 4) where the cross section gets more surface sensitive by switching from dipolar to impact regime ${ }^{79}$. The inverse of the modulus of the wave vector transfer parallel to the surface gives an estimate of the probing depth ${ }^{79}$ :

$$
k_{\|}=\frac{\sqrt{2 m E_{I}}}{\hbar} \sin \Theta_{I}-\frac{\sqrt{2 m\left(E_{I}-\hbar \omega\right)}}{\hbar} \sin \Theta_{S}
$$

where $E_{I}$ is the incident electron energy, $\hbar \omega$ the energy loss, $2 \pi \hbar$ the Planck constant, $\Theta_{I}$ and $\Theta_{S}$ the incident and scattering angle, respectively (Sect. S3 in Supplemental Material ${ }^{59}$ ). BGS were recorded off-specular at $300 \mathrm{~K}$, before and after $20 \mathrm{~L} \mathrm{O}_{2}$ exposure, on $\mathrm{R}-\mathrm{TiO}_{2}$ (Fig. 4a) and $\mathrm{SA}_{-} \mathrm{TiO}_{2}$ (Fig. S5 in Supplemental Material $\left.^{59}\right)$. Data were normalized to interband transitions whose probing depth does not change significantly with $\Theta_{S}$ (Fig. 4a-inset and Fig. S2c in Supplemental Material $\left.^{59}\right)$. The dramatic decrease in BGS intensity with $\Theta_{S}$ shows that excess charges are not located at 

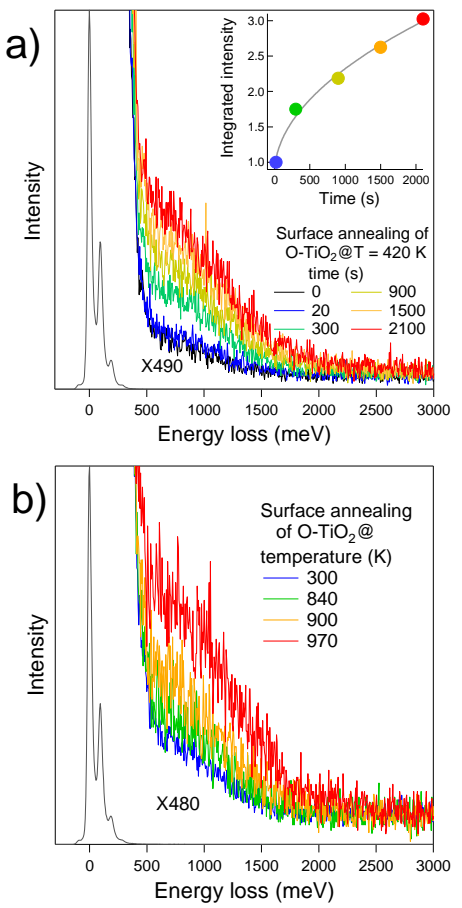

FIG. 2. Singling out BGS from $\mathrm{Ti}_{\text {int }}$ by surface annealing of $\mathrm{O}-\mathrm{TiO}_{2}$. EELS measurements at $300 \mathrm{~K}$ : a) BGS recorded on SA-420K- $\mathrm{TiO}_{2}$ versus time; inset: time evolution of the BGS area (500-2500 meV) fitted by a square-root function; b) BGS from $\mathrm{SA}-\mathrm{TiO}_{2}$ prepared at different temperatures during $10 \mathrm{~s}$; c) BGS recorded upon successive treatments (step 1 to 4): surface annealing (10 s) at given temperatures (strong color) and then $20 \mathrm{~L}$ of $\mathrm{O}_{2}$ (light color) at $300 \mathrm{~K}$ (from bottom to top). Inset: BGS intensities step by step: black dotted lines show the order of treatments, the orange and blue eye-guide arrows evidence an increase in BGS intensity upon increase in annealing temperature and a corresponding decrease in residual intensity after $20 \mathrm{~L} \mathrm{O}_{2}$.
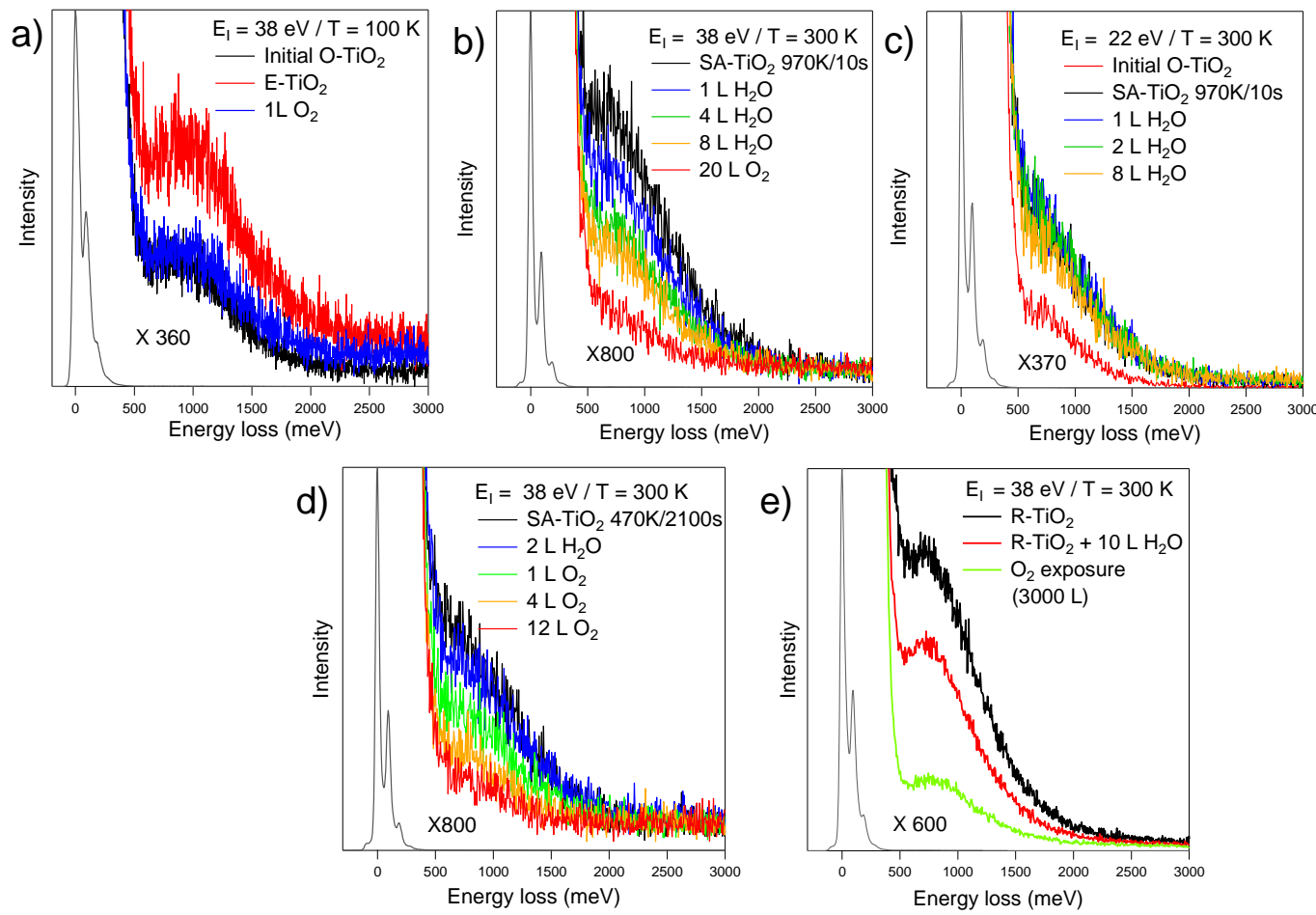

FIG. 3. Distinguishing V-BGS from I-BGS by exposure to $\mathrm{H}_{2} \mathrm{O}$ and $\mathrm{O}_{2}$ : a) BGS of a E-TiO $\mathrm{O}_{2}$ surface are totally healed by $1 \mathrm{~L}$ of $\mathrm{O}_{2}$ at $100 \mathrm{~K}$; b) BGS of SA-970K-TiO $\mathrm{T}_{2}$ surface $\left(10 \mathrm{~s}\right.$ annealing) are healed at $300 \mathrm{~K}$ by $\mathrm{H}_{2} \mathrm{O}$ under an electron beam at $38 \mathrm{eV}$; c) Same experiment as in b), but at $22 \mathrm{eV}$; d) BGS of SA-470K-TiO 2 (2100 s annealing) at $300 \mathrm{~K}$ are not affected by $\mathrm{H}_{2} \mathrm{O}$ under electrons at $38 \mathrm{eV}$ but, in contrast, are healed by $\mathrm{O}_{2}$; e) BGS from $\mathrm{R}-\mathrm{TiO}_{2}$ are partially healed at $300 \mathrm{~K}$ by $\mathrm{H}_{2} \mathrm{O}$ under electrons at $38 \mathrm{eV}$ an even more cancelled by further $\mathrm{O}_{2}$ exposure. 

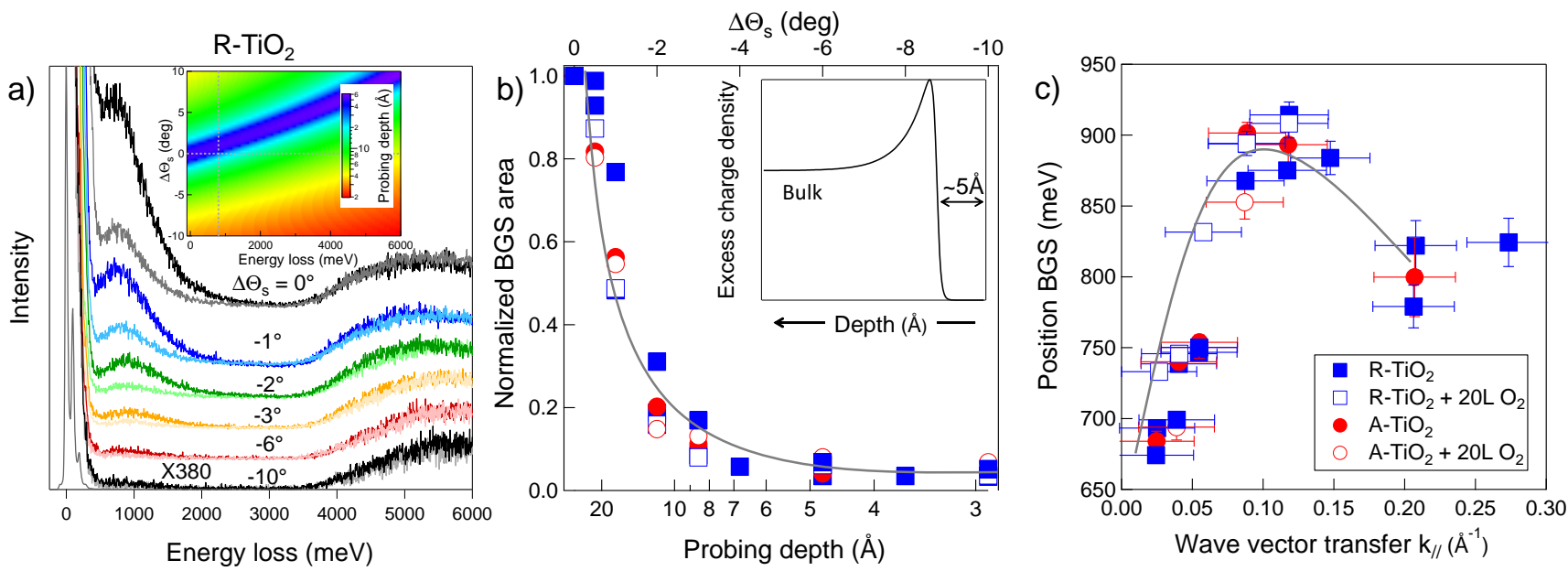

FIG. 4. Concentration profile and dispersion of BGS at $300 \mathrm{~K}$ : a) BGS of $\mathrm{R}-\mathrm{TiO}_{2}$ at different collection angles relative to specular direction $\Delta \Theta_{S}=\Theta_{S}-\Theta_{I}$ at fixed incidence $\Theta_{I}=60^{\circ}$, as prepared (strong color) and after exposure to $20 \mathrm{~L}$ of $\mathrm{O}_{2}$ (light color); inset: calculated off-specular probing depth (see text) averaged over a detector aperture of $\sim 1^{\circ}$ versus energy loss and angular position $\Delta \Theta_{S}$ at fixed incident angle at an energy of $38 \mathrm{eV}$; the grey dotted lines correspond to specular geometry and to BGS energy loss; b) BGS area normalized to that recorded in specular geometry (maximum probing depth) versus probing depth (bottom scale) and $\Delta \Theta_{S}$ (top): $\mathrm{R}-\mathrm{TiO}_{2}$ and $\mathrm{SA}-970 \mathrm{~K}-\mathrm{TiO}_{2}$, as prepared and after $20 \mathrm{~L}$ of $\mathrm{O}_{2}$ at $300 \mathrm{~K}$, are compared. Inset: schematic concentration profile of excess electrons in the subsurface region; c) Dispersion of the position of the BGS with the wave vector transfer $k_{\|} \cdot k_{\|}$-error stems from a detector aperture of $\sim 1^{\circ}$. Grey lines in (b,c) are guide for eyes. Color codes for $(\mathrm{b}, \mathrm{c})$ are given in $(\mathrm{c})$.

the extreme surface, as confirmed by the poor effect of $\mathrm{O}_{2}$ at the highest $\Theta_{S}$. Normalized BGS area versus probing depth from $\mathrm{R}-\mathrm{TiO}_{2}$ and $\mathrm{SA}-\mathrm{TiO}_{2}$ (Fig. 4b) and BGS positions versus $k_{\|}$(Fig. 4c) show that the four series of data are streakingly similar (Fig. 4b,c). This shows that the electron localization and state dispersion are independent of whether they are related to $\mathrm{O}_{b}$-vac ( $\mathrm{R}-\mathrm{TiO}_{2}$ and $\mathrm{SA}-\mathrm{TiO}_{2}$ ) or to $\mathrm{Ti}_{\text {int }}$ (after $\mathrm{O}_{2}$ exposure). Generalizing previous theory ${ }^{80}$ and experiment ${ }^{61}$, the observation directly proves that the surface/subsurface electrostatic potentials dictate the location of the excess charges. A unique representation of the charge distribution can be drawn for all surfaces, either reduced or oxidized (Fig. 4b-inset). Going inward, after an almost charge-free atomic layer, excess charges pass through a maximum, consistently with photoelectron diffraction $^{60,61}$ and calculations ${ }^{62-64,78,81}$. Going deeper, the defect density lowers to reach the bulk value. The dispersive trend up to a cut-off of $k_{\|} \sim 0.1 \AA^{-1}$ (Fig. 4c), demonstrates the transport behavior of excess electrons down to a distance $(\sim 10 \AA)$ that can be interpreted as the polaron radius at $300 \mathrm{~K}^{63,64,76,78,81,82}$.
To summarize, vacancy- and interstitial-related BGS have been singled out by EELS experiments based on annealing only the very surface. The associated excess electrons contribute to a unique subsurface distribution whose profile and dispersive behavior are robust with respect to the nature of the defects. In contrast, their role in surface chemistry relies on the specificity of the defects. The dual origin of BGS allows the understanding of seemingly contradictory observations and opens up new ways of interpreting experiments carried out on $\mathrm{TiO}_{2}$ surfaces.

\section{ACKNOWLEDGMENTS}

J. L. acknowledges the Chinese Scholarship Council for his $\mathrm{PhD}$ grant. J. L. did the experimental measurements under the supervision of R. L. S. C. brought all the required technical assistance. J. L., R. L. and J. J contributed to interpretations and wrote the manuscript. R. L and J. J. designed the research strategy.

\footnotetext{
* jingfeng.li1987@gmail.com

† Corresponding author :remi.lazzari@insp.jussieu.fr

¥ stephane.chenot@insp.jussieu.fr

$\S$ jacques.jupille@insp.jussieu.fr
}

42 A. Fujishima, X. Zhang, and D. Tryk, Surf. Sci. Rep. 63, 515 (2008).

43 M. A. Henderson, Surf. Sci. Rep. 66, 185 (2011).

${ }^{44}$ U. Diebold, Surf. Sci. Rep. 48, 53 (2003). 
45 S. Wendt, P. T. Sprunger, E. Lira, G. K. H. Madsen, Z. Li, J. O. Hansen, J. Matthiesen, A. Blekinge-Rasmussen, E. Laegsgaard, B. Hammer, et al., Science 320, 1755 (2008).

46 Z. Dohnálek, I. Lyubinetsky, and R. Rousseau, Prog. Surf. Sci. 85, 161 (2010).

47 C. L. Pang, R. Lindsay, and G. Thornton, Chem. Rev. 113, 3887 (2013).

48 V. E. Henrich, G. Dresselhaus, and H. J. Zeiger, Phys. Rev. Lett. 36, 1335 (1976)

49 H. Onishi and Y. Iwasawa, Phys. Rev. Lett. 76, 791 (1996).

50 M. Li, W. Hebenstreit, L. Gross, U. Diebold, M. A. Henderson, D. R. Jennison, P. A. Schultz, and M. P. Sears, Surf. Sci. 437, 173 (1999).

51 E. Lira, J. Hansen, P. Huo, R. Bechstein, P. Galliker, E. Lægsgaard, B. Hammer, S. Wendt, and F. Besenbacher, Surf. Sci. 604, 1945 (2010).

52 E. Lira, S. Wendt, P. Huo, J. Ø. Hansen, R. Streber, S. Porsgaard, Y. Wei, R. Bechstein, E. Lægsgaard, and F. Besenbacher, J. Am. Chem. Soc. 133, 6529 (2011).

${ }^{53}$ E. Lira, P. Huo, J. Ø. Hansen, F. Rieboldt, R. Bechstein, Y. Wei, R. Streber, S. Porsgaard, Z. Li, E. Lægsgaard, et al., Catal. Today 182, 25 (2012).

54 M. A. Henderson, W. S. Epling, C. L. Perkins, C. H. F. Peden, and U. Diebold, J. Phys. Chem. B 103, 5328 (1999).

55 A. C. Papageorgiou, N. S. Beglitis, C. L. Pang, G. Teobaldi, G. Cabailh, Q. Chen, A. J. Fisher, W. A. Hofer, and G. Thornton, Proc. Natl. Acad. Sci. USA 107, 2391 (2010).

56 N. G. Petrik, Z. Zhang, Y. Du, Z. Dohnálek, I. Lyubinetsky, and G. A. Kimmel, J. Phys. Chem. C 113, 12407 (2009).

57 C. M. Yim, C. L. Pang, and G. Thornton, Phys. Rev. Lett. 104, 036806 (2010).

58 E. Cho, S. Han, H. S. Ahn, K.-R. Lee, S. K. Kim, and C. H. Hwang, Phys. Rev. B 73, 193202 (2006).

59 See Supplemental Material at URLXXX for a description of a) the experimental set-up, b) the annealing of the surface by a hot filament placed in front of the sample, c) the determination of the probing depth in EELS and d) complementary figures.

${ }^{60}$ P. Krüger, S. Bourgeois, B. Domenichini, H. Magnan, D. Chandesris, P. Le Fèvre, A. M. Flank, J. Jupille, L. Floreano, A. Cossaro, et al., Phys. Rev. Lett. 100, 055501 (2008).

61 P. Krüger, J. Jupille, S. Bourgeois, B. Domenichini, A. Verdini, L. Floreano, and A. Morgante, Phys. Rev. Lett. 108, 126803 (2012)

62 S. Chrétien and H. Metiu, J. Phys. Chem. C 115, 4696 (2011).

63 N. A. Deskins, R. Rousseau, and M. Dupuis, J. Phys. Chem. C 115, 7562 (2011).

${ }^{64}$ P. M. Kowalski, M. F. Camellone, N. N. Nair, B. Meyer, and D. Marx, Phys. Rev. Lett. 105 (2010).

${ }^{65}$ R. Lazzari, J. Li, and J. Jupille, Rev. Sci. Instrum. 86, 013906 (2015).

66 M. A. Henderson, W. S. Epling, C. H. F. Peden, and C. L. Perkins, J. Phys. Chem. B 107, 534 (2003).

67 M. A. Henderson, Surf. Sci. 419, 174 (1999).

${ }^{68}$ Z. Zhang, J. Lee, J. T. Yates, R. Bechstein, E. Lira, J. Hansen, S. Wendt, and F. Besenbacher, J. Phys. Chem. C 114, 3059 (2010).

${ }^{69}$ K. Mitsuhara, H. Okumura, A. Visikovskiy, M. Takizawa, and Y. Kido, J. Chem. Phys. 136, 124707 (2012).
70 S. Wendt, R. Schaub, J. Matthiesen, E. Vestergaard, E. Wahlström, M. Rasmussen, P. Thostrup, L. Molina, E. Lægsgaard, I. Stensgaard, et al., Surf. Sci. 598, 226 (2005).

71 M. L. Knotek and P. J. Feibelman, Phys. Rev. Lett. 40, 964 (1978).

72 J. Lee, Z. Zhang, and J. T. Yates, Phys. Rev. B 79, 081408 (2009).

73 S. Wendt, R. Bechstein, S. Porsgaard, E. Lira, J. . Hansen, P. Huo, Z. Li, B. Hammer, and F. Besenbacher, Phys. Rev. Lett. 104, 259703 (2010).

74 C. M. Yim, C. L. Pang, and G. Thornton, Phys. Rev. Lett. 104, 259704 (2010).

75 K. Onda, B. Li, and H. Petek, Phys. Rev. B 70, 0455415 (2004).

76 T. Minato, Y. Sainoo, Y. Kim, H. S. Kato, K. Aika, M. Kawai, J. Zhao, H. Petek, T. Huang, W. He, et al., J. Chem. Phys. 130, 124502 (2009).

77 N. A. Deskins, R. Rousseau, and M. Dupuis, J. Phys. Chem. C 113, 14583 (2009).

78 P. G. Moses, A. Janotti, C. Franchini, G. Kresse, and C. G. Van de Walle, J. Appl. Phys. 119, 181503 (2016), http://dx.doi.org/10.1063/1.4948239.

79 H. Ibach and D. L. Mills, Electron Energy Loss Spectroscopy and Surface Vibrations (Academic Press, New York, 1982).

80 T. Albaret, F. Finocchi, C. Noguera, and A. De Vita, Phys. Rev. B 65, 035402 (2001).

81 C. M. Yim, M. B. Watkins, M. J. Wolf, C. L. Pang, K. Hermansson, and G. Thornton, Phys. Rev. Lett. 117, 116402 (2016).

82 M. Setvin, C. Franchini, X. Hao, M. Schmid, A. Janotti, M. Kaltak, G. Van de Walle, G. Kresse, and U. Diebold, Phys. Rev. Lett. 113, 086402 (2014).

42 A. Fujishima, X. Zhang, and D. Tryk, Surf. Sci. Rep. 63, 515 (2008).

43 M. A. Henderson, Surf. Sci. Rep. 66, 185 (2011), ISSN 0167-5729.

44 U. Diebold, Surf. Sci. Rep. 48, 53 (2003).

${ }^{45}$ S. Wendt, P. T. Sprunger, E. Lira, G. K. H. Madsen, Z. Li, J. O. Hansen, J. Matthiesen, A. Blekinge-Rasmussen, E. Laegsgaard, B. Hammer, et al., Science 320, 1755 (2008), ISSN 1095-9203.

46 Z. Dohnálek, I. Lyubinetsky, and R. Rousseau, Prog. Surf. Sci. 85, 161 (2010), ISSN 0079-6816.

47 C. L. Pang, R. Lindsay, and G. Thornton, Chem. Rev. 113, 3887 (2013), ISSN 1520-6890.

48 V. E. Henrich, G. Dresselhaus, and H. J. Zeiger, Phys. Rev. Lett. 36, 1335 (1976).

49 H. Onishi and Y. Iwasawa, Phys. Rev. Lett. 76, 791 (1996).

50 M. Li, W. Hebenstreit, L. Gross, U. Diebold, M. A. Henderson, D. R. Jennison, P. A. Schultz, and M. P. Sears, Surf. Sci. 437, 173 (1999).

51 E. Lira, J. Hansen, P. Huo, R. Bechstein, P. Galliker, E. Lægsgaard, B. Hammer, S. Wendt, and F. Besenbacher, Surf. Sci. 604, 1945 (2010).

52 E. Lira, S. Wendt, P. Huo, J. Ø. Hansen, R. Streber, S. Porsgaard, Y. Wei, R. Bechstein, E. Lægsgaard, and F. Besenbacher, J. Am. Chem. Soc. 133, 6529 (2011).

${ }^{53}$ E. Lira, P. Huo, J. Ø. Hansen, F. Rieboldt, R. Bechstein, Y. Wei, R. Streber, S. Porsgaard, Z. Li, E. Lægsgaard, et al., Catal. Today 182, 25 (2012).

54 M. A. Henderson, W. S. Epling, C. L. Perkins, C. H. F. Peden, and U. Diebold, J. Phys. Chem. B 103, 5328 (1999), 
ISSN 1520-5207.

55 A. C. Papageorgiou, N. S. Beglitis, C. L. Pang, G. Teobaldi, G. Cabailh, Q. Chen, A. J. Fisher, W. A. Hofer, and G. Thornton, Proc. Natl. Acad. Sci. USA 107, 2391 (2010).

56 N. G. Petrik, Z. Zhang, Y. Du, Z. Dohnálek, I. Lyubinetsky, and G. A. Kimmel, J. Phys. Chem. C 113, 12407 (2009).

57 C. M. Yim, C. L. Pang, and G. Thornton, Phys. Rev. Lett. 104, 036806 (2010), ISSN 1079-7114.

58 E. Cho, S. Han, H. S. Ahn, K.-R. Lee, S. K. Kim, and C. H. Hwang, Phys. Rev. B 73, 193202 (2006).

59 See Supplemental Material at URLXXX for a description of a) the experimental set-up, b) the annealing of the surface by a hot filament placed in front of the sample, c) the determination of the probing depth in EELS and d) complementary figures.

60 P. Krüger, S. Bourgeois, B. Domenichini, H. Magnan, D. Chandesris, P. Le Fèvre, A. M. Flank, J. Jupille, L. Floreano, A. Cossaro, et al., Phys. Rev. Lett. 100, 055501 (2008), ISSN 1079-7114.

61 P. Krüger, J. Jupille, S. Bourgeois, B. Domenichini, A. Verdini, L. Floreano, and A. Morgante, Phys. Rev. Lett. 108, 126803 (2012).

${ }^{62}$ S. Chrétien and H. Metiu, J. Phys. Chem. C 115, 4696 (2011).

63 N. A. Deskins, R. Rousseau, and M. Dupuis, J. Phys. Chem. C 115, 7562 (2011), ISSN 1932-7447.

${ }^{64}$ P. M. Kowalski, M. F. Camellone, N. N. Nair, B. Meyer, and D. Marx, Phys. Rev. Lett. 105 (2010), ISSN 10797114 .

${ }^{65}$ R. Lazzari, J. Li, and J. Jupille, Rev. Sci. Instrum. 86, $013906(2015)$

${ }^{66}$ M. A. Henderson, W. S. Epling, C. H. F. Peden, and C. L. Perkins, J. Phys. Chem. B 107, 534 (2003), ISSN 15205207.

67 M. A. Henderson, Surf. Sci. 419, 174 (1999).

68 Z. Zhang, J. Lee, J. T. Yates, R. Bechstein, E. Lira, J. Hansen, S. Wendt, and F. Besenbacher, J. Phys. Chem. C 114, 3059 (2010), ISSN 1932-7455.
${ }^{69}$ K. Mitsuhara, H. Okumura, A. Visikovskiy, M. Takizawa, and Y. Kido, J. Chem. Phys. 136, 124707 (2012), ISSN 0021-9606.

70 S. Wendt, R. Schaub, J. Matthiesen, E. Vestergaard, E. Wahlström, M. Rasmussen, P. Thostrup, L. Molina, E. Lægsgaard, I. Stensgaard, et al., Surf. Sci. 598, 226 (2005), ISSN 0039-6028.

71 M. L. Knotek and P. J. Feibelman, Phys. Rev. Lett. 40, 964 (1978).

72 J. Lee, Z. Zhang, and J. T. Yates, Phys. Rev. B 79, 081408 (2009), ISSN 1550-235X.

73 S. Wendt, R. Bechstein, S. Porsgaard, E. Lira, J. . Hansen, P. Huo, Z. Li, B. Hammer, and F. Besenbacher, Phys. Rev. Lett. 104, 259703 (2010), ISSN 1079-7114.

74 C. M. Yim, C. L. Pang, and G. Thornton, Phys. Rev. Lett. 104, 259704 (2010).

75 K. Onda, B. Li, and H. Petek, Phys. Rev. B 70, 0455415 (2004), ISSN 1550-235X.

76 T. Minato, Y. Sainoo, Y. Kim, H. S. Kato, K. Aika, M. Kawai, J. Zhao, H. Petek, T. Huang, W. He, et al., J. Chem. Phys. 130, 124502 (2009), ISSN 0021-9606.

77 N. A. Deskins, R. Rousseau, and M. Dupuis, J. Phys. Chem. C 113, 14583 (2009), ISSN 1932-7455.

78 P. G. Moses, A. Janotti, C. Franchini, G. Kresse, and C. G. Van de Walle, J. Appl. Phys. 119, 181503 (2016), http://dx.doi.org/10.1063/1.4948239.

79 H. Ibach and D. L. Mills, Electron Energy Loss Spectroscopy and Surface Vibrations (Academic Press, New York, 1982)

80 T. Albaret, F. Finocchi, C. Noguera, and A. De Vita, Phys. Rev. B 65, 035402 (2001).

81 C. M. Yim, M. B. Watkins, M. J. Wolf, C. L. Pang, K. Hermansson, and G. Thornton, Phys. Rev. Lett. 117, 116402 (2016).

${ }^{82}$ M. Setvin, C. Franchini, X. Hao, M. Schmid, A. Janotti, M. Kaltak, G. Van de Walle, G. Kresse, and U. Diebold, Phys. Rev. Lett. 113, 086402 (2014). 


\title{
SUPPLEMENTARY INFORMATION Contributions of oxygen vacancies and titanium interstitials to the band gap states of reduced titania
}

\author{
Jingfeng Li, ${ }^{*}$ Rémi Lazzari, ${ }^{\dagger}$ Stéphane Chenot, ${ }^{\ddagger}$ and Jacques Jupille ${ }^{\S}$ \\ CNRS, UMR 7588, Institut des NanoSciences de Paris, 75005 Paris, France and \\ Sorbonne Universités, UPMC Univ Paris 06, UMR 7588, \\ Institut des NanoSciences de Paris, 75005 Paris, France
}

(Dated: November 28, 2017)

The supplementary information describes the experimental set-up (Sect. I), the annealing of the surface by a hot filament placed in front of the sample (Sect. II), the determination of the probing depth in electron energy loss spectroscopy (Sect. III). It also involves complementary figures (Sect. IV).

\section{EXPERIMENTAL}

Experiments were performed in an ultra-high vacuum vessel $^{1}$ including a preparation chamber equipped with a LEED-Auger device (Low Energy Electron Diffraction) (base pressure $3.10^{-10}$ mbar) and a main chamber (base pressure $5.10^{-11}$ mbar) housing a High Resolution Electron Energy Loss spectrometer (HREELS). The thermal contact between the $\mathrm{TiO}_{2}$ sample (from Mateck $\mathrm{GmbH}^{2}$ ) and the metallic backplate was insured by firmly clamping the double-side polished substrate onto the polished backplate with an intermediate gold foil in between. $\mathrm{TiO}_{2}(110)$ surfaces were prepared through several cycles of sputtering/annealing in vacuum $(1 \mathrm{keV} / 1100 \mathrm{~K})$ until reaching a sharp $(1 \times 1)$ LEED pattern and a surface free of contaminants as judged from Auger spectroscopy and EELS signal. The stoichiometry defects in these reduced sample $\left(\mathrm{R}-\mathrm{TiO}_{2}\right)$ yielded a sufficiently high conductivity to prevent any charge effect during measurements.

EELS experiments have been performed with a LK2000 spectrometer $^{3,4}$ which consists of a dual cylindrical monochromator at $127^{\circ}$ and a rotating analyzer ${ }^{5}$. While the incident angle is fixed at $\Theta_{I}=60^{\circ}$, the collection angle can be changed from $\Theta_{S}=20^{\circ}$ to $\Theta_{S}=70^{\circ}$. Most EELS spectra have been acquired along the specular direction at a beam energy of $E_{I}=38 \mathrm{eV}$ with a resolution around $50 \mathrm{meV}$ as given by the full-width at half-maximum of the elastic peak (counting rate close to $10^{6} \mathrm{~s}^{-1}$ ). The beam energy was slightly higher than the minimum energy of the Ti $3 p$ core level excitation of the Auger transition (32-34 eV) for vacancy creation by the Knotek-Feibelmann process ${ }^{6,7}$. However, as estimated from the cross section of the literature at this energy, any sizable beam damage is excluded since it would require several days of exposure at the current density of a few tens of $\mathrm{nA}$ which is used herein. Test experiments after irradiation over a time scale much larger than regular experiments showed no Band-Gap States (BGS) inten- sity change. Complementary phonon spectra recorded in HREELS at higher resolution (around $8 \mathrm{meV}, E_{I}=8 \mathrm{eV}$, counting rate $>10^{5} \mathrm{~s}^{-1}$ ) were used to determine surface temperature during annealing with a filament (see Sect. II). Surface exposure was performed by backfilling the EELS chamber with research-grade pure $\mathrm{O}_{2}$ and distilled $\mathrm{H}_{2} \mathrm{O}$ that was outgased through several pump-freeze cycles. Exposure are given in Langmuir, $1 \mathrm{~L}$ corresponding to an exposure of $1.3310^{-6}$ mbar.s ${ }^{-1}$. Cooling at $100 \mathrm{~K}$ was achieved through a copper braid connecting the end of the 5-axis manipulator of the EELS chamber and a tank cooled through circulating liquid nitrogen. All spectra have been acquired with the scattering plane perpendicular to the oxygen bridging rows i.e. along the $[1 \overline{1} 0]$ bulk direction. BGS area and position have been determined through a Lorentzian fit of peaks between 500 and $2500 \mathrm{meV}$. As described in Refs. 8-10, three Fuchs-Kliewer phonons at 45, 55 and $95 \mathrm{meV}$ and their multiple/combination excitations dominate the loss spectrum of $\mathrm{TiO}_{2}(110)$ at low energy losses before the BGS and the onset of interband transitions above $3.2 \mathrm{eV}$ (see for instance Fig.4-a of the article).

Besides the above mentioned reduced $\mathrm{R}-\mathrm{TiO}_{2}$ surface, several types of $\mathrm{TiO}_{2}(110)$ surface preparations were used. $\mathrm{R}-\mathrm{TiO}_{2}$ could be reoxidised $\left(\mathrm{O}-\mathrm{TiO}_{2}\right)$ by annealing 30 mins at $1100 \mathrm{~K}$ and cooling down to $300 \mathrm{~K}$, both in $\mathrm{O}_{2}\left(p=5 \times 10^{-6}\right.$ mbar $)$, a treatment known to induce a regrowth of surface $\mathrm{TiO}_{2}$ islands by diffusion of $\mathrm{Ti}_{\text {int }}$ and to heal $\mathrm{O}_{b}$-vac ${ }^{11,12}$ (rate $\sim 30 \mathrm{~K} \cdot \mathrm{min}^{-1}$ ). A E-TiO surface was prepared by electron bombardment with a defocused electron beam (current of $\sim 1 \mu \mathrm{A} . \mathrm{cm}^{-2}$, beam energy of $75 \mathrm{eV}$ to increase the oxygen electron stimulated desorption cross section) produced by an ancillary electron gun that was well-degased prior to be used by irradiating the sample manipulator head; most importantly, the distance to the sample and the screening of the gun filament exclude any sample heating (See Section II). The last preparation (labeled $\mathrm{SA}-\mathrm{TiO}_{2}$ ) consisted in annealing only the sample surface by means of a hot filament placed in front of the crystal. It is described in what follows. 


\section{SURFACE ANNEALING WITH A FILAMENT}

In the EELS measurement position, the surface could be radiatively heated in a controlled way by means of a tungsten filament set in front of the grounded sample. Those samples of which Surfaces have been Annealed at temperature T (K) are labelled SA-T-TiO2. Prior to thermal treament, the filament as well as the sample manipulator were carefully outgased, and during surface heating, the chamber pressure kept in the low $10^{-10}$ mbar; no burst of pressure upon switching on the filament was observed. After treatment, no trace of contamination was found by Auger spectroscopy (by photoemission performed in an other vacuum system) and the EELS spectrum could be cycled reversibly back and forth with oxygen exposure. Surface temperature could be changed by modifying either the filament-surface distance (a few mms to $20 \mathrm{~mm}$ ) or the filament power (up to $25 \mathrm{~W}$ ). Such a surface annealing avoids the surface/bulk thermal equilibrium which is established during annealing by the back of the sample. An additional advantage of the HREELS technique is the ability to determine the temperature of the surface during annealing through the Bose-Einstein distribution of losses and gains in the phonon region ${ }^{13-21}$. Their ratio is given by the Boltzmann factor $\exp \left(-\hbar \omega / k_{B} T\right)$ where $\hbar \omega$ is the energy loss/gain and $k_{B}$ the Boltzmann constant (Fig. S1-a). The obtained stationary temperature corresponds to that of the near surface region, and more precisely to the EELS probing depth of phonon losses which typically amounts to about ten nanometers (see Sect. III and Fig. S2-b). A reproducible calibration specific to the present work could be performed as a function of the filament power $P$ at fixed filament-sample distance $d$ (Fig. S1-b) or as a function of the distance at fixed power (Fig. S1-c). Temperatures could not be measured beyond $650 \mathrm{~K}$ (Fig. S1-c) because the trajectories of the HREELS electron beam were too strongly perturbed by the filament to maintain a reasonable counting rate. Therefore, extrapolated values were used from the fitted $T \sim P / d^{2}$ behavior (Figs. S1-b,c).

Creation of defects through spurious electrons emitted by the filament ${ }^{6,7,22-24}$ is excluded. Indeed, a surface was annealed at high temperature by the hot filament which was either grounded or polarized at $+100 \mathrm{~V}$ to insure that absolutely no electrons were emitted. The overlapping EELS spectra confirmed that only heating affects the BGS intensity. In addition, no change could be observed when the filament was negatively polarized to illuminate the surface by electrons which means that, within the specific geometry of the filament-substrate used herein, annealing effects fully dominate. Generally speaking, these observations suggest that care must be taken to avoid surface annealing when creating point defects by electron bombardment.

BGS increase through atomic hydrogen adsorption due to thermal cracking of residual background molecules
$\left(\mathrm{H}_{2}, \mathrm{H}_{2} \mathrm{O}\right)$ on the hot filament can be ruled out from a straigthforward evaluation of the order of magnitude of exposure. Assuming a perfect dissociation coefficient $\left(\mathrm{H}_{2} \rightarrow 2 \mathrm{H}\right)$ over the whole filament surface of $1 \mathrm{~mm}^{2}$ (length $60 \mathrm{~mm}$, diameter $=0.15 \mathrm{~mm}$ ), a partial pressure of $\mathrm{H}_{2}$ of $\sim 10^{-10}$ mbar would give a yield of $2.210^{9} \mathrm{H}$ atom.s ${ }^{-1}$ (the impinging rate is given by $p / \sqrt{2 \pi m k T}$; $\mathrm{T}=300 \mathrm{~K})$. Since the solid angle of the sample $\left(1 \mathrm{~cm}^{2}\right)$ seen from the filament (in the punctual filament approximation!) is around $0.02 \mathrm{rad}$ (distance of $2 \mathrm{~cm}$ during the low temperature annealing), only $4.410^{7} \mathrm{H}$ atom. $\mathrm{cm}^{-2} \cdot \mathrm{s}^{-1}$ can reach the surface. Since the monolayer $\left(\mathrm{ML}\left(\mathrm{O}_{b}\right)\right)$ of bridging oxygen row is $510^{14} \mathrm{~cm}^{-2}$, the creation of $0.1 \mathrm{ML}\left(\mathrm{O}_{b}\right)$ would require an exposure of $1.110^{6} \mathrm{~s}$ which is already $\sim 500$ times the longest exposure performed in our experiments. Indeed, literature shows that to obtain significant effect of atomic hydrogen on $\mathrm{TiO}_{2}$ by dissociation on heated tungsten, exposures that are orders of magnitude above ours are required ${ }^{25,26}$.

In the present work, two specific annealing conditions were chosen: (i) $420 \mathrm{~K}$ where creation of $\mathrm{O}_{b}$-vac cannot happen, but diffusion of $\mathrm{Ti}_{\text {int }}$ is possible ${ }^{12,27-30}$ and (ii) around $1000 \mathrm{~K}$ where the creation of $\mathrm{O}_{b}$-vac is systematically observed by bulk annealing ${ }^{31-37}$. Two durations were compared: (i) a short one $(t=10 \mathrm{~s})$ mainly at the highest temperature corresponding to a flash annealing and (ii) longer ones (up to $t>1000 \mathrm{~s}$ ). When flash annealing at high temperature, any increase of the temperature has never been observed as measured by the thermocouple on our manipulator. After annealing the sample for $2100 \mathrm{~s}$ at $420 \mathrm{~K}$, this measured "bulk" temperature was increased by only few degrees over a sample thickness of $0.5 \mathrm{~mm}$. This gradient of temperature is due to the thermal mass of the $\mathrm{Cu}$ manipulator that acts as a thermal sink. Upon a short annealing of $10 \mathrm{~s}$, a simple square root of time estimate indicates that a similar temperature increase would be observed at a distance of a few tens of microns of the surface and that, consequently the depth at which the temperature is homogeneous is much below the micron. All surface annealing treatments were performed on samples that had been oxidized by saturating amounts of oxygen at room temperature. The term "saturation" has a relative sense. It corresponds to exposures high enough to heal the largest part of the BGS intensity (i.e. at least $20 \mathrm{~L}$ at $300 \mathrm{~K}$ ), as shown in Fig. S3.

\section{PROBING DEPTH AND SPECTRA NORMALIZATION}

In an EELS experiments, an incoming electron of wave vector $\mathbf{k}_{I}$ and incident energy $E_{I}=\hbar^{2} k_{I}^{2} / 2 m(m$ mass of the electron, $2 \pi \hbar$ Planck constant) is scattered along a wave vector $\mathbf{k}_{S}$ and looses/gains an energy $\hbar \omega$ $\left(E_{S}=\hbar^{2} k_{S}^{2} / 2 m=E_{I} \pm \hbar \omega\right)$ before being detected by 

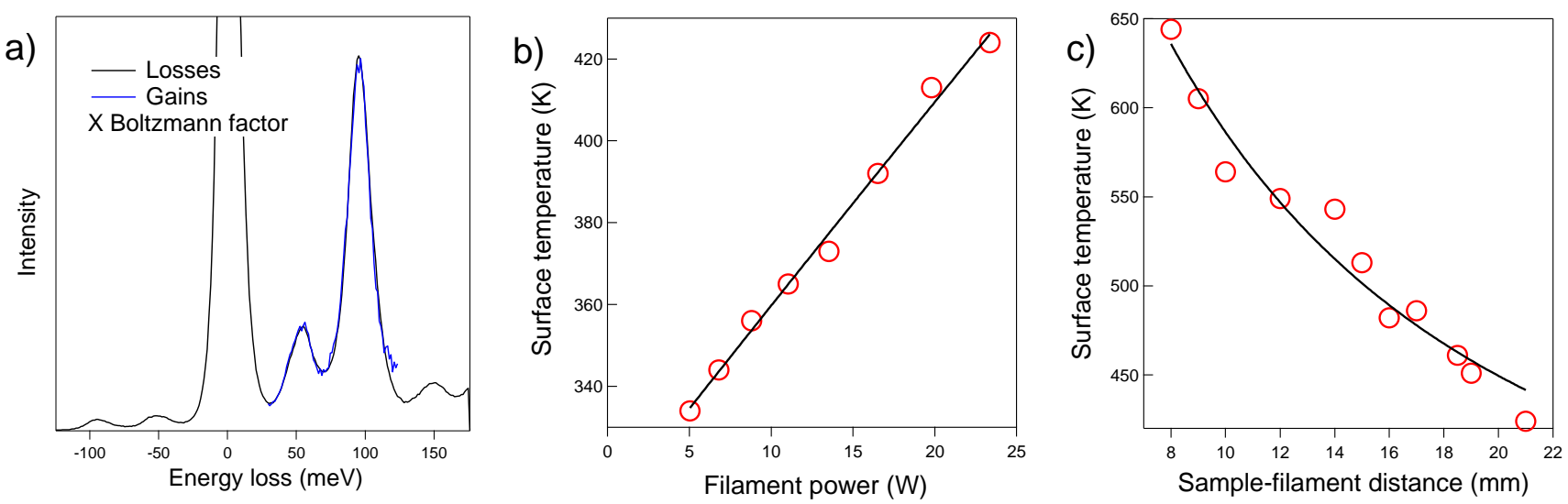

FIG. S1. a) HREELS spectrum of the phonon losses (black line) of $\mathrm{TiO}_{2}(110)$ overlapped with the folded gains (blue line) multiplied by the Boltzmann factor. The accuracy of the temperature determination is of the order of $1 \mathrm{~K}$. Spectra have been recorded at a beam energy of $E_{I}=8 \mathrm{eV}$ and a resolution $\sim 8 \mathrm{meV}$ in the specular geometry. Measured surface temperature (red circles) b) versus filament power $P$ at fixed sample-filament distance $d=20 \mathrm{~mm}$ or c) versus $d$ at fixed $P=23 \mathrm{~W}$. Best fits with a $T \sim P / d^{2}$ behavior are shown as black lines.

a spectrometer of acceptance $\theta_{c}$. By moving the detector away from the specular direction, the interaction between the electron beam and the surface changes progressively from a long-range dipolar mode to a shortrange impact scattering regime. The depth sensitivity of the measurement depends on the impact energy $E_{I}$, the energy loss $\hbar \omega$ and scattering geometry defined by the incident angle $\Theta_{I}$, the average scattering angle $\Theta_{S}$ and the polar coordinates $\left(\theta_{S}, \phi_{S}\right)$ that span the collection aperture $\theta_{c}$ of the detector (see Fig. S2-a). There is no precise definition of the probing depth in electron energy loss spectroscopy ${ }^{13,38}$. Indeed, the successfull dielectric theory ${ }^{13-21}$ that accounts for the dipolar scattering for $\Theta_{I}=\Theta_{S}$ shows a complex interplay between the profile of dielectric function and the cross section of energy loss through an angular integration over the so-called sensitivity function. But a reasonable estimate ${ }^{38}$ is given by the evanescent decay length $d_{p}$ of the electric field produced by the moving electron and through which it interacts with the substrate ${ }^{13-21}$. It is worth noticing that this probing depth is quite different from photoemission spectroscopy for which it is based on an escape depth of inelastically scattered electrons. According to the dielectric theory ${ }^{13-21}, d_{p}$ is given by the inverse of the parallel wave vector transfer of the electron $k_{\|}=\left(k_{S}-k_{I}\right) \sin \Theta_{I}$ along the specular trajectory. To first order in energy $\operatorname{loss}\left(\theta_{E}=\hbar \omega / 2 E_{I} \ll 1\right), d_{p}\left(\theta_{E}, \Theta_{I}\right)=1 /\left(k_{I} \theta_{E} \sin \Theta_{I}\right)$ is inversely proportional to the energy loss $\hbar \omega$ and the higher the beam energy the larger the probing depth. $d_{p}$ has been plotted in Fig. S2-b for two beam energies $E_{I}=8$ and $38 \mathrm{eV}$ corresponding to high and low resolution measurements as performed in this work. It is also compared to its average over a typical circular detector aperture $^{5,13}$ of $\theta_{c}=1^{\circ}$ as defined by:

$$
\begin{aligned}
\left\langle d_{p}\right\rangle\left(\theta_{E}, \Theta_{I}, \theta_{c}\right) & =\frac{1}{\pi \theta_{c}^{2}} \int_{0}^{\theta_{c}} \theta_{S} d \theta_{S} \int_{0}^{2 \pi} d \phi_{S} d_{p}\left(\theta_{E}, \Theta_{I}, \theta_{S}, \phi_{S}\right) \\
\frac{1}{d_{p}\left(\theta_{E}, \Theta_{I}, \theta_{S}, \phi_{S}\right)} & =k_{I}\left[\left(\theta_{E} \sin \Theta_{I}-\theta_{S} \cos \phi_{S} \cos \Theta_{I}\right)^{2}\right. \\
& \left.+\left(\theta_{S} \sin \phi_{S}\right)^{2}\right]^{1 / 2}
\end{aligned}
$$

The main effect of this detector integration is to smear out the nonphysical divergence at zero loss (Fig. S2b,c; circles vs lines). Because of the bulk sensitivity of the phonon losses $\left(\left\langle d_{p}\right\rangle \simeq 100 \AA\right.$ at $E_{I}=8 \mathrm{eV}$ and $\left\langle d_{p}\right\rangle \simeq 50 \AA$ at $\left.E_{I}=38 \mathrm{eV}\right)$, specular spectra have been normalized throughout this work to the most intense phonon peak around $100 \mathrm{meV}$. Indeed, due to gas interaction with the filament of the EELS apparatus, absolute counting rate evolves during gas exposure. At the BGS energy, EELS at $E_{I}=38 \mathrm{eV}$ probes the subsurface $\left(\left\langle d_{p}\right\rangle \simeq 30 \AA\right)$ and it becomes very surface sensitive in the case of interband transitions $\left(\left\langle d_{p}\right\rangle<10 \AA\right)$.

Regarding out-of-specular measurements, the definition of the probing depth is even less straightforward since there is a continuous transition from a strongly peaked long-range dipolar interaction close to the specular direction to a short-range impact interaction. Formally, the calculation of the loss cross section changes from an efficient description by the dielectric theory to more complex quantum mechanical treatment. But, owing to the same underlying electrostatic interaction between the electron and the sample, this transition of probing depth is still well accounted by the inverse of the wave vector transfer 
a) EELS scattering geometry

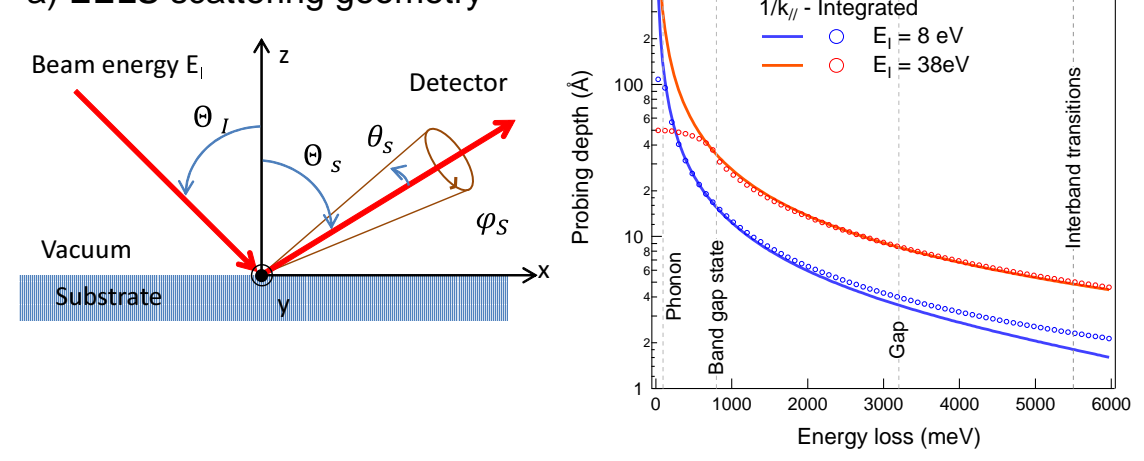

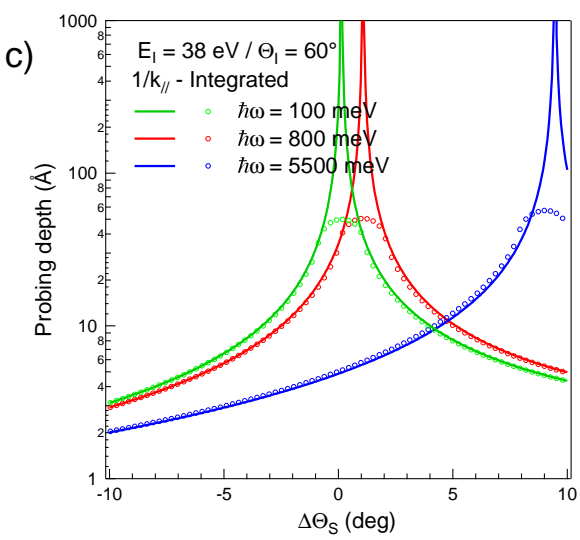

FIG. S2. a) Scattering geometry in an (HR)EELS experiment. An incoming electron of impact energy $E_{I}$ impinges on the surface of the substrate at an incident angle $\Theta_{I}$; it is scattered off along a direction coplanar to the z-axis defined by its angles $\left(\Theta_{S}, \theta_{s}, \phi_{s}\right) .\left(\Theta_{I}=\Theta_{S}, \theta_{s}=0\right)$ corresponds to the specular scattering geometry. Along its path, the electron exchanges quanta of energy $\hbar \omega \ll E_{I}$ with the substrate and is subjected to a total in-plane wave vector transfer $k_{\|}$. b) Probing depth $d_{p}$ in the specular scattering geometry $\left(\Theta_{I}=\Theta_{S}=60^{\circ}\right)$ as function of energy loss $\hbar \omega$ at the two impact energies $E_{I}=8$ and 38 eV (blue/red) used in this work. $d_{p}$ and $\left\langle d_{p}\right\rangle$ (see text for definition) are compared. Typical loss energies for phonons, BGS, band gap or interband transitions are highlighted as grey dotted lines. c) Same as Fig. b but in out-of-specular geometry as a function of $\Delta \Theta_{S}=\Theta_{S}-\Theta_{I}$ for three energy losses representative of the phonon $(\hbar \omega=100 \mathrm{meV})$, BGS $(\hbar \omega=800 \mathrm{meV})$ and interband transitions $(\hbar \omega=5500 \mathrm{meV})$. In Figs. b,c, the maxima corresponds to conditions for which $k_{\|}$is close to zero.

$d_{p}^{o s}=1 / k_{\|}^{o s}($ Fig. S2-a) given by:

$$
\begin{aligned}
& k_{\|}^{o s}\left(\theta_{E}, \Theta_{I}, \Theta_{S}, \theta_{s}, \phi_{S}\right)= \\
& k_{I}\left[\left(\theta_{E} \sin \Theta_{S}+\sin \Theta_{I}-\sin \Theta_{S}-\theta_{S} \cos \phi_{S} \cos \Theta_{S}\right)^{2}\right. \\
& \left.+\left(\theta_{S} \sin \phi_{S}\right)^{2}\right]^{1 / 2}
\end{aligned}
$$

as well as the corresponding integrated value $\left\langle d_{p}^{o s}\right\rangle$ over the detector aperture. As shown in the inset of Fig. 4a of the paper and reminded in Fig. S2-c, $\left\langle d_{p}^{o s}\right\rangle$ at an energy loss typical for BGS ( $\hbar \omega=800 \mathrm{meV}$ ) quickly drops from $30 \AA$ down to $2 \AA$ as soon as the detection angle $\Theta_{S}$ is in off-specular direction. To avoid the resonant condition seen for $\Delta \Theta_{S}>0$ corresponding to $k_{\|}^{o s}\left(\theta_{s}=0\right)=0$ i.e. $\sin \Theta_{S}=\sin \Theta_{I} /\left(1+\theta_{E}\right)$ and to be more surface sensitive at all energies, data have been recorded only for negative offset $\Delta \Theta_{S}<0$ (see Fig. 4-a of the paper and Fig. S5). At the opposite to phonon losses (Fig. S2-c, green curves), the probing depth for interband transitions does not change significantly for $\Delta \Theta_{S}<0$ (Fig. S2-c, blue curves); therefore, this energy range has been used to normalize spectra and to analyse the depth dependence of BGS intensity in out-of-specular geometry (Fig. 4-b of the paper). The overlapping of spectra above the band gap validates a posteriori this assumption.

\section{COMPLEMENTARY FIGURES}

* jingfeng.li1987@gmail.com

$\dagger$ Corresponding author :remi.lazzari@insp.jussieu.fr

¥ stephane.chenot@insp.jussieu.fr

$\S$ jacques.jupille@insp.jussieu.fr

1 R. Lazzari, J. Li, and J. Jupille. Spectral restoration in reflection energy electron loss spectroscopy based on iterative semi-blind Lucy-Richardson algorithm applied to rutile surfaces. Rev. Sci. Instrum., 86:013906, 2015.

${ }^{2}$ http://www.physik.de/mateck. site for single cristal substrates.

${ }^{3}$ http://www.lktech.com/products/lk2000.php.

${ }^{4}$ L.L. Kesmodel. New high resolution electron spectrometer for surface vibrational analysis. J. Vac. Sci. Technol. A, $1: 1456-1460,1983$.
${ }^{5}$ H. Ibach. Electron Energy Loss Spectrometers: The technology of high performance. Springer-Verlag, 1991.

6 J. Lee, Z. Zhang, and J. T. Yates. Electron-stimulated positive-ion desorption caused by charge transfer from adsorbate to substrate: oxygen adsorbed on $\mathrm{TiO}_{2}(110)$. Phys. Rev. B, 79:081408, 2009.

7 M. L. Knotek and P. J. Feibelman. Ion desorption by corehole Auger decay. Phys. Rev. Lett., 40:964-967, 1978.

${ }^{8}$ P. A. Cox, R. G. Edgell, S. Eriksen, and W. R. Flavell. The high resolution electron energy loss spectrum of $\mathrm{TiO}_{2}(110)$. J. Electron. Spectrosc. and Relat. Phenom., 39:117-126, 1986.

9 S. Eriksen and R. G. Egdell. Electronic excitations at oxygen deficient $\mathrm{TiO}_{2}(110)$ surfaces: a study by EELS. Surf. Sci., 180:263-278, 1987. 

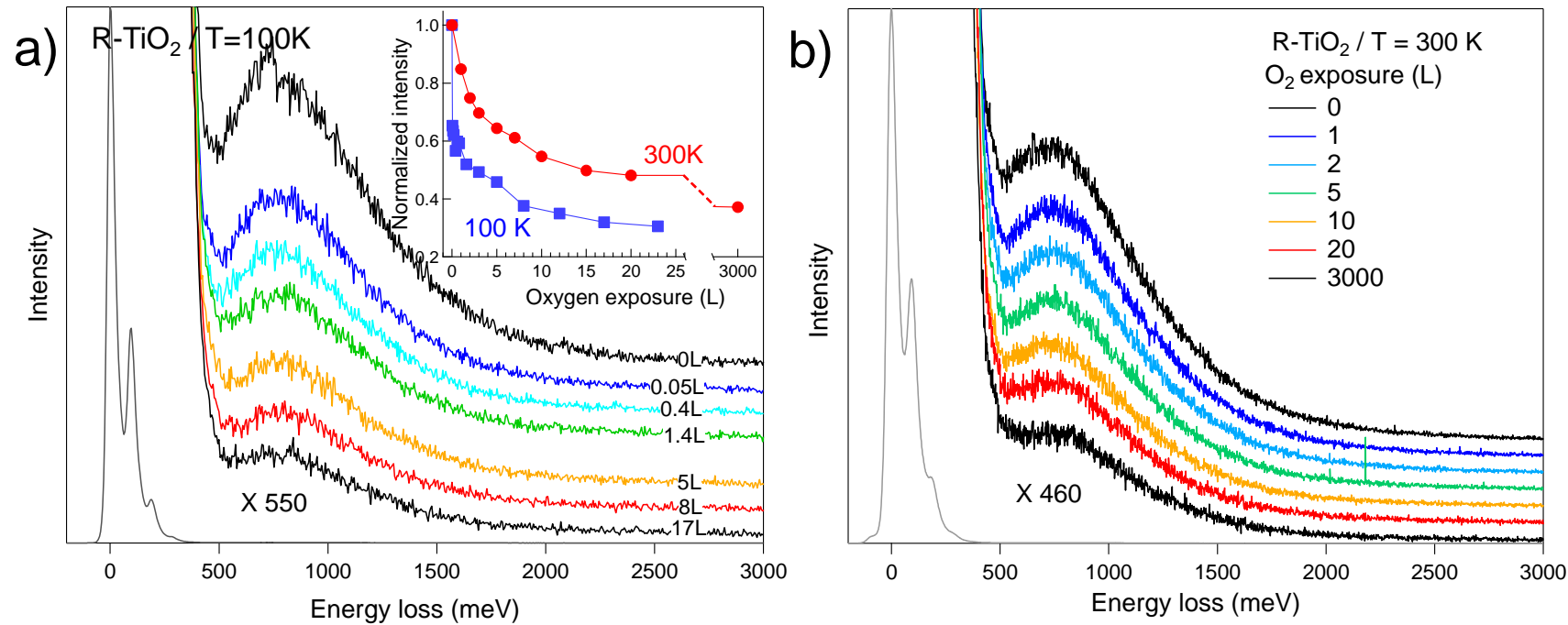

FIG. S3. Evolution of the intensity of BGS of $\mathrm{R}-\mathrm{TiO}_{2}$ upon $\mathrm{O}_{2}$ exposure given in figure at a) $100 \mathrm{~K}$ and b) $300 \mathrm{~K}$. Curves are offset for clarity. The healing of the BGS is much slower at $300 \mathrm{~K}$. Inset of Fig. a shows the variation as a function of $\mathrm{O}_{2}$ exposure of the BGS area (integrated intensity) between 500 and $2500 \mathrm{meV}$ (normalized to the initial values) at $100 \mathrm{~K}$ (blue squares) and $300 \mathrm{~K}$ (red circles).

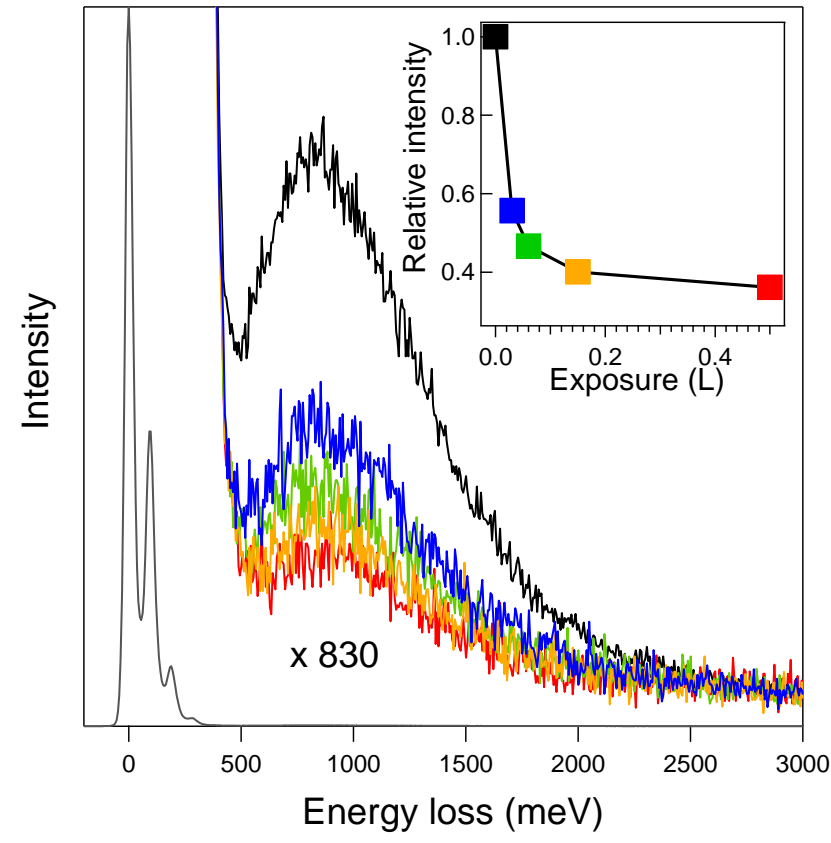

FIG. S4. Evolution of EELS spectra in the BGS region of a $\mathrm{SA}-\mathrm{TiO}_{2}$ surface annealed during $10 \mathrm{~s}$ at $970 \mathrm{~K}$ upon $\mathrm{O}_{2}$ exposure at $100 \mathrm{~K}$. The inset showing the evolution of the BGS integrated intensity demonstrates the very fast healing of BGS created by surface annealing.

10 M. A. Henderson. An HREELS and TPD study of water on $\mathrm{TiO}_{2}(110)$ : the extent of molecular versus dissociative adsorption. Surf. Sci., 355:151-166, 1996.

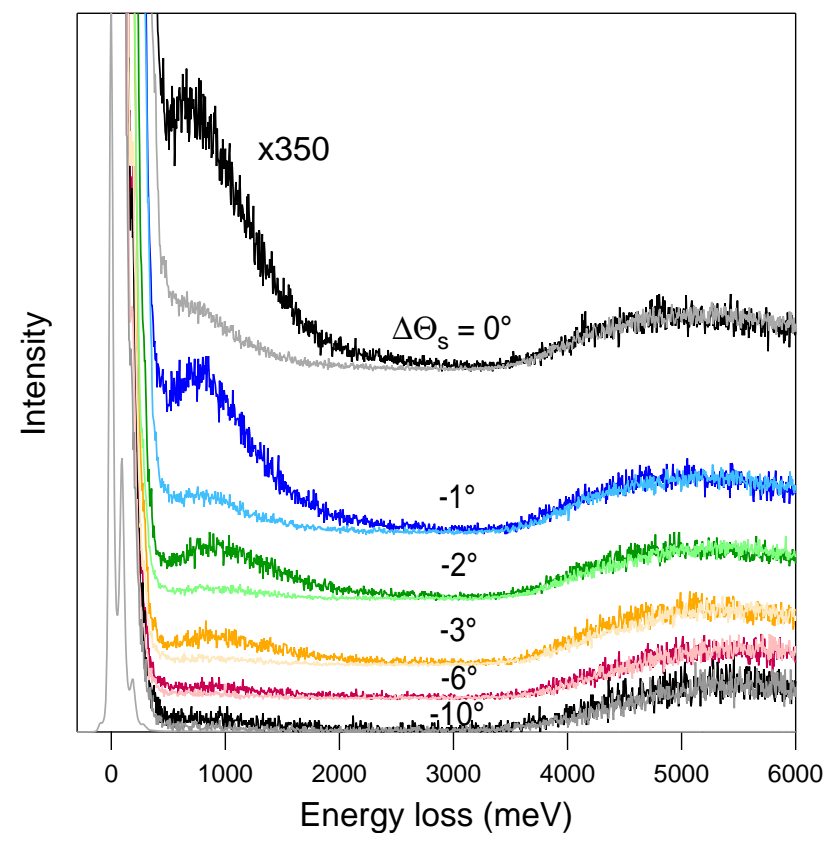

FIG. S5. Out-of-specular EELS measurements of BGS of a $\mathrm{SA}-\mathrm{TiO}_{2}$ surface annealed during $10 \mathrm{~s}$ at $970 \mathrm{~K}$ before (full line) and after exposure (light line) to $20 \mathrm{~L}$ of $\mathrm{O}_{2}$ at $300 \mathrm{~K}$. The offset angle $\Delta \Theta_{s}=\Theta_{S}-\Theta_{I}$ is indicated in figure. The corresponding evolutions of integrated intensities are displayed in Fig. 4-b of the article.

11 H. Onishi and Y. Iwasawa. Dynamic visualization of a metal-oxide-surface/gas-phase reaction: time-resolved observation by scanning tunneling microscopy at $800 \mathrm{~K}$. 
Phys. Rev. Lett., 76:791-794, 1996.

12 M. Li, W. Hebenstreit, L. Gross, U. Diebold, M. A. Henderson, D. R. Jennison, P. A. Schultz, and M. P. Sears. Oxygen-induced restructuring of the $\mathrm{TiO}_{2}(110)$ surface: a comprehensive study. Surf. Sci., 437:173-190, 1999.

${ }^{13}$ H. Ibach and D. L. Mills. Electron Energy Loss Spectroscopy and Surface Vibrations. Academic Press, New York, 1982.

14 A. A. Lucas and M. Sunjić. Fast-electron spectroscopy of surface excitations. Phys. Rev. Lett., 26:229-232, 1971.

15 A. A. Lucas and M. Sunjić. Fast-electron spectroscopy of collective excitations in solids. Prog. Surf. Sci., 2:75-137, 1972.

16 E. Evans and D. L. Mills. Theory of inelastic scattering of slow electrons by long-wavelength surface optical phonons. Phys. Rev. B, 5:4126-4139, 1972.

17 E. Evans and D. L. Mills. Theory of inelastic scattering of slow electrons by long-wavelength surface of optical phonons: multiphonon processes. Phys. Rev. B, 7:853-868, 1973.

18 D. L. Mills. The scattering of low energy electrons by electric field fluctuations near crystal surfaces. Surf. Sci., 48:59-79, 1975.

19 A. A. Lucas and J. P. Vigneron. Theory of electron energy loss spectroscopy from surfaces of anisotropic materials. Solid. Stat. Comm., 49:327-330, 1984.

${ }^{20} \mathrm{Ph}$. Lambin, J. P. Vigneron, and A. A. Lucas. Electronenergy-loss spectroscopy of multilayered materials: theoretical aspects and study of interface optical phonons in semiconductor superlattices. Phys. Rev. B, 32(12):8203$8215,1985$.

21 P. A. Thiry, M. Liehr, J.-J. Pireaux, and R. Caudano. Electron interaction mechanisms in high resolution electron energy loss spectroscopy. Phys. Scripta, 35:368-379, 1987.

${ }^{22}$ C. L. Pang, O. Bikondoa, D. S. Humphrey, A. C. Papageorgiou, G. Cabailh, R. Ithnin, Q. Chen, C. A. Muryn, H. Onishi, and G. Thornton. Tailored $\mathrm{TiO}_{2}(110)$ surfaces and their reactivity. Nanotechnology, 17:5397-5405, 2006.

23 N. G Petrik, Z. Zhang, Y. Du, Z. Dohnálek, I. Lyubinetsky, and G. A. Kimmel. Chemical reactivity of reduced $\mathrm{TiO}_{2}(110)$ : the dominant role of surface defects in oxygen chemisorption. J. Phys. Chem. C, 113(28):12407-12411, 2009.

${ }^{24}$ C. M. Yim, C. L. Pang, and G. Thornton. Oxygen vacancy origin of the surface band-gap state of $\mathrm{TiO}_{2}(110)$. Phys. Rev. Lett., 104:036806, 2010.
25 J. Tao, Q. Cuan, X.-Q. Gong, and M. Batzill. Diffusion and reaction of hydrogen on rutile $\mathrm{TiO}_{2}(011)-(2 \times 1)$ : the role of surface structure. J. Phys. Chem. C, 116:20438-20446, 2012.

${ }^{26}$ K. Fukada, M. Matsumoto, K. Takeyasu, S. Ogura, and K. Fukutani. Effects of hydrogen on the electronic state and electric conductivity of the rutile $\mathrm{TiO}_{2}(110)$ surface. Journal of the Physical Society of Japan, 84:064716, 2015.

27 H. Iddir, S. Ögüt, P. Zapol, and N. D. Browning. Diffusion mechanisms of native point defects in rutile $\mathrm{TiO}_{2}: A b i n i-$ tio total-energy calculations. Phys. Rev. B, 75(7):073203, 2007.

28 S. Wendt, P. T. Sprunger, E. Lira, G. K. H. Madsen, Z. Li, J. O. Hansen, J. Matthiesen, A. Blekinge-Rasmussen, E. Laegsgaard, B. Hammer, and F. Besenbacher. The role of interstitial sites in the Ti3d defect state in the band gap of titania. Science, 320:1755-1759, 2008.

29 Z. Zhang, J. Lee, J. T. Yates, R. Bechstein, E. Lira, J. Hansen, St. Wendt, and F. Besenbacher. Unraveling the diffusion of bulk Ti interstitials in rutile $\mathrm{TiO}_{2}(110)$ by monitoring their reaction with $\mathrm{O}$ adatoms. J. Phys. Chem. C, 114(7):3059-3062, 2010.

${ }^{30}$ K. Mitsuhara, H. Okumura, A. Visikovskiy, M. Takizawa, and Y. Kido. The source of the Ti $3 \mathrm{~d}$ defect state in the band gap of rutile titania (110) surfaces. J. Chem. Phys., 136:124707, 2012.

31 U. Diebold. The surface science of titanium dioxide. Surf. Sci. Rep., 48:53, 2003.

32 C. Lun Pang, R. Lindsay, and G. Thornton. Chemical reactions on rutile $\mathrm{TiO}_{2}(110)$. Chem. Soc. Rev., 37:2328, 2008.

33 L.-M. Liu, P. Crawford, and P. Hu. The interaction between adsorbed $\mathrm{OH}$ and $\mathrm{O}_{2}$ on $\mathrm{TiO}_{2}$ surfaces. Prog. Surf. Sci., 84:155-176, 2009.

34 Z. Dohnálek, I. Lyubinetsky, and R. Rousseau. Thermallydriven processes on rutile $\mathrm{TiO}_{2}(110)-(1 \mathrm{x} 1)$ : A direct view at the atomic scale. Prog. Surf. Sci., 85(5-8):161-205, 2010.

35 M. A. Henderson. A surface science perspective on $\mathrm{TiO}_{2}$ photocatalysis. Surf. Sci. Rep., 66:185-297, 2011.

36 C. L. Pang, R. Lindsay, and G. Thornton. Structure of clean and adsorbate-covered single-crystal rutile $\mathrm{TiO}_{2}$ surfaces. Chem. Rev., 113:3887-3948, 2013.

37 M. A. Henderson and I. Lyubinetsky. Molecular-level insights into photocatalysis from scanning probe microscopy studies on $\mathrm{TiO}_{2}(110)$. Chem. Rev., 113:4428-4455, 2013.

38 M. Noguchi, K. Hirakawa, and T. Ikoma. In situ determination of electronic properties of clean $\mathrm{GaAs}(100)$ surfaces by high-resolution electron energy loss spectroscopy. Surf. Sci., 271:260-276, 1992. 